Supporting information

\title{
Dehydrogenation of Methane by Partially Oxidized Tungsten Cluster Cations: High Reactivity Comparable to That of Platinum Cluster Cations
}

\author{
Shinichi Hirabayashi ${ }^{\dagger}$ and Masahiko Ichihashi**‡ \\ ${ }^{\dagger}$ East Tokyo Laboratory, Genesis Research Institute, Inc., 717-86 Futamata, \\ Ichikawa, Chiba 272-0001, Japan \\ ${ }^{\ddagger}$ Cluster Research Laboratory, Toyota Technological Institute: in East Tokyo \\ Laboratory, Genesis Research Institute, Inc., 717-86 Futamata, Ichikawa, Chiba \\ 272-0001, Japan
}



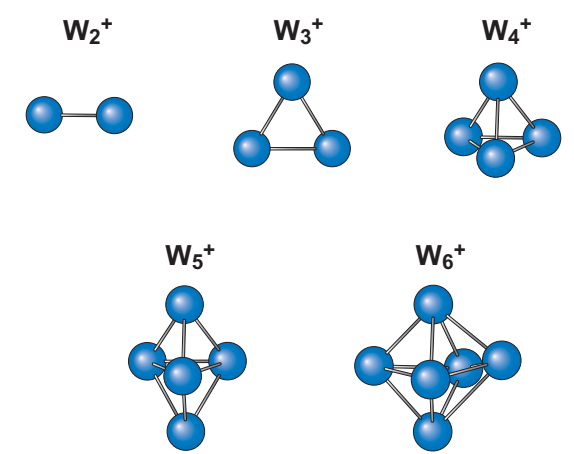

Figure S1. Optimized structures of the lowest-energy isomers for $\mathrm{W}_{n}^{+}(n=2-6)$.

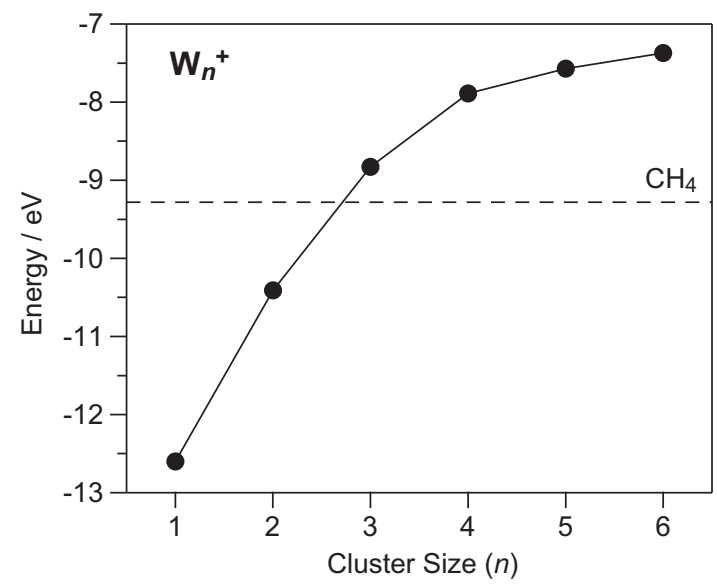

Figure S2. Calculated energies of SOMOs for $\mathrm{W}_{n}{ }^{+}(n=1-6)$ as a function of the cluster size. For comparison, the calculated HOMO energy of $\mathrm{CH}_{4}$ is also indicated as a horizontal dashed line. 


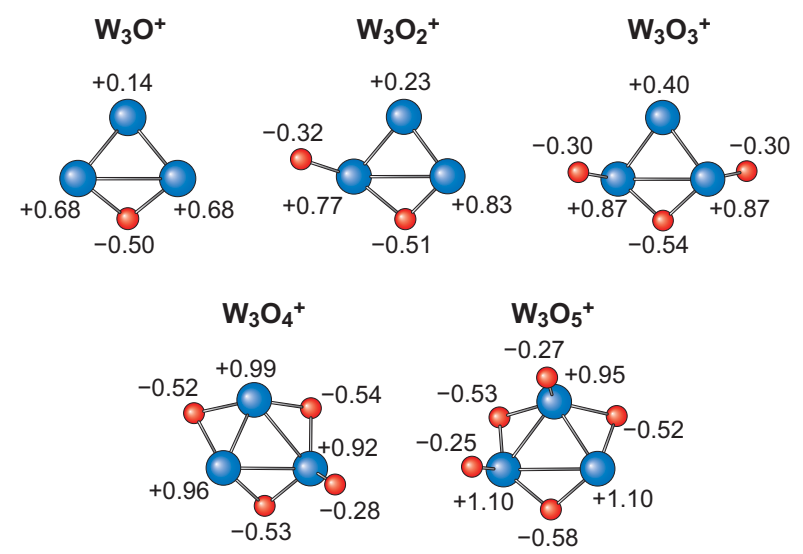

Figure S3. Optimized structures of the lowest-energy isomers for $\mathrm{W}_{3} \mathrm{O}_{m}{ }^{+}(m=1-5)$. The Mulliken charges are also shown.

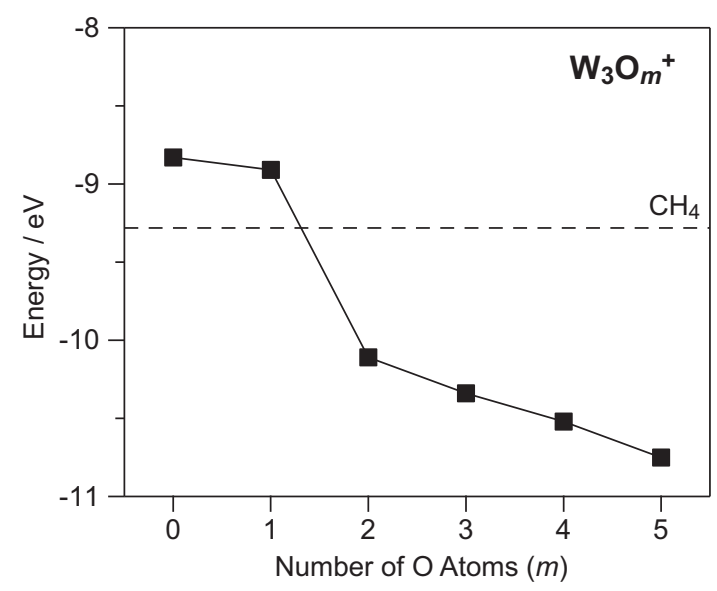

Figure S4. Calculated energies of SOMOs for $\mathrm{W}_{3} \mathrm{O}_{m}{ }^{+}(m=0-5)$ as a function of the number of $\mathrm{O}$ atoms. For comparison, the calculated HOMO energy of $\mathrm{CH}_{4}$ is also indicated as a horizontal dashed line. 


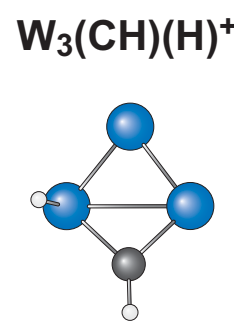

$-0.13 \mathrm{eV}$
$\mathrm{W}_{3}\left(\mathrm{CH}_{2}\right)^{+}$

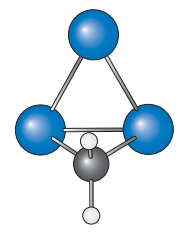

$+0.13 \mathrm{eV}$

Figure S5. Optimized structures of the lowest-energy isomers for $\mathrm{W}_{3}(\mathrm{CH})(\mathrm{H})^{+}$and $\mathrm{W}_{3}\left(\mathrm{CH}_{2}\right)^{+}$. The numbers show the energies of the products, $\mathrm{W}_{3}(\mathrm{CH})(\mathrm{H})^{+}+\mathrm{H}_{2}$ and $\mathrm{W}_{3}\left(\mathrm{CH}_{2}\right)^{+}+\mathrm{H}_{2}$, with respect to the energy of the reactants, $\mathrm{W}_{3}{ }^{+}+\mathrm{CH}_{4}$. 